OPEN ACCESS

Edited by:

Alberto Biondi,

Catholic University of the Sacred

Heart, Italy

Reviewed by:

Ravindra Deshpande,

Wake Forest School of Medicine,

United States

Emanuele Rinninella,

Catholic University of the Sacred

Heart, Italy

*Correspondence:

Jie Lin

linjie1992@zju.edu.cn

${ }^{\dagger}$ These authors have contributed equally to this work

Specialty section:

This article was submitted to Gastrointestinal Cancers,

a section of the journal

Frontiers in Oncology

Received: 13 March 2021 Accepted: 09 June 2021

Published: 24 June 2021

Citation:

Gu L, Zhang Y, Hong J, Xu B, Yang L, Yan K, Zhang J, Chen P, Zheng J and Lin J (2021) Prognostic Value of Pretreatment Overweight/Obesity and

Adipose Tissue Distribution in Resectable Gastric Cancer: A Retrospective Cohort Study.

Front. Oncol. 11:680190. doi: 10.3389/fonc.2021.680190

\title{
Prognostic Value of Pretreatment Overweight/Obesity and Adipose Tissue Distribution in Resectable Gastric Cancer: A Retrospective Cohort Study
}

Lihu $\mathrm{Gu}^{1,2,3 \dagger}$, Yangfan Zhang ${ }^{4 \dagger}$, Jiaze Hong ${ }^{5}$, Binbin Xu' ${ }^{6}$, Liuqiong Yang ${ }^{4}$, Kun Yan $^{7}$, Jingfeng Zhang ${ }^{2,7}$, Ping Chen ${ }^{1}$, Jianjun Zheng ${ }^{2,7}$ and Jie Lin ${ }^{8 *}$

1 Department of General Surgery, HwaMei Hospital, University of Chinese Academy of Sciences, Ningbo, China, 2 Ningbo Institute of Life and Health Industry, University of Chinese Academy of Sciences, Ningbo, China, ${ }^{3}$ Key Laboratory of Diagnosis and Treatment of Digestive System Tumors of Zhejiang Province, HwaMei Hospital, University of Chinese Academy of Sciences, Ningbo, China, ${ }^{4}$ Ningbo University School of Medicine, Ningbo, China, ${ }^{5}$ The Second Clinical Medical College, Zhejiang Chinese Medical University, Hangzhou, China, ${ }^{6}$ Department of Nutrition, HwaMei Hospital, University of Chinese Academy of Sciences, Ningbo, China, ${ }^{7}$ Department of Radiology, HwaMei Hospital, University of Chinese Academy of Sciences, Ningbo, China, ${ }^{8}$ Department of Thoracic Surgery, HwaMei Hospital, University of Chinese Academy of Sciences, Ningbo, China

Background: This is a study aimed at exploring the relationship between pretreatment overweight/obesity, adipose tissue distribution, and long-term prognosis of gastric cancer.

Methods: A total of 607 gastric cancer patients were involved in the retrospective cohort study. Overweight/obese patients were defined as body mass index (BMI) greater than 25 $\mathrm{kg} / \mathrm{m}^{2}$, and adipose tissue distribution parameters, including visceral adipose tissue (VAT), subcutaneous adipose tissue (SAT), and VAT/SAT ratio were measured the level of the third lumbar vertebra using computerized tomography images within 15 days before the surgery. Multiple Cox regression models were applied to evaluate the association between overweight/obesity and disease-specific survival (DSS) of gastric cancer, and covariates including age, gender, T stage, $\mathrm{N}$ stage, and chemotherapy were adjusted. Furthermore, multiple Cox regression models were performed to evaluate the association between adipose tissue distribution parameters and DSS of gastric cancer; except for covariates mentioned above, overweight/obesity was adjusted additionally.

Results: Overweight/obesity was a predictive factor ( $\mathrm{HR}=0.61,95 \% \mathrm{Cl}: 0.37-0.99)$ for the prognosis of gastric cancer. After additionally adjusting for overweight/obesity, high SAT percentage was an independent protective factor ( $\mathrm{HR}=0.59,95 \% \mathrm{Cl}: 0.36-0.96)$, while high VAT percentage $(\mathrm{HR}=1.68,95 \% \mathrm{Cl}: 1.06-2.68)$ and high VAT/SAT ratio (HR= 1.99, 95\% Cl: 1.19-3.34) were independent risk factors for DSS of gastric cancer. Compared with other patients (overweight/obesity with low VAT/SAT ratio group, nonoverweight/obesity or high VAT/SAT ratio group), patients in the non-overweight/obesity with high VAT/SAT ratio group had a worse prognosis ( $\mathrm{HR}=1.89,95 \% \mathrm{Cl}: 1.28-2.77)$. 


\begin{abstract}
Conclusion: These results suggest that overweight/obesity is a predictive factor for the prognosis of gastric cancer. The VAT/SAT ratio could be used as a promising prognostic factor for gastric cancer. Therefore, in preoperative evaluation of gastric cancer patients, attention should be paid not only to BMI but also to adipose tissue distribution.
\end{abstract}

Keywords: overweight, obesity, adipose tissue distribution, gastric cancer, prognosis

\section{INTRODUCTION}

Gastric cancer is the fifth most commonly diagnosed malignancy and the fourth leading cause of death from cancer worldwide (1). At present, the main treatment for resectable gastric cancer is surgery combined with adjuvant therapy, especially chemotherapy (2). However, the long-term prognosis of advanced gastric cancer is not satisfactory (3). The correlation between obesity and the prognosis of gastric cancer has always been controversial (4). Previous studies have shown that obese patients with gastric cancer have better long-term survival than non-overweight/obese patients $(5,6)$. However, several studies have shown that obesity is not associated with survival in gastric cancer (7-9). In most studies, obesity was used as an adjuvant parameter and was not further analyzed. Besides, when considering the association between obesity and the prognosis of gastric cancer patients, we should not only consider "obesity" defined by body mass index (BMI), but also consider the relationship between the adipose tissue distribution and gastric cancer, including the relationship between the content or distribution of adipose tissue and gastric cancer.

There are certain differences in the adipose tissue distribution; even in the same BMI population, the adipose tissue distribution in the body is not the same. However, studies on the effect of adipose tissue distribution on the long-term prognosis of gastric cancer are largely lacking. Human adipose tissue mainly includes visceral adipose tissue (VAT) and subcutaneous adipose tissue (SAT), and their effects on tumors vary (10). Although obesity was initially found to confer a survival advantage in cancer patients, mounting evidence suggests that increased visceral adipose tissue may negatively influence survival in patients with numerous cancers $(11,12)$. In contrast, current studies have found that SAT is protective and associated with the prognosis of various tumors, including colorectal cancer (13), prostate cancer (14), head and neck cancer (15), and hepatocellular carcinoma (16).

In recent years, increased visceral adiposity has been associated with the prognosis of various tumors (17-19). However, the association between visceral adiposity and the prognosis of gastric cancer involves retrospective studies with small sample sizes, and the results remain controversial (20). Computed tomography (CT) scan is routinely used in the diagnosis and treatment of gastric cancer. Besides, CT is the gold standard method for adipose tissue component analysis due

Abbreviations: BMI, body mass index; VAT, visceral adipose tissue; SAT, subcutaneous adipose tissue; DSS, disease-specific survival; CT, computed tomography; SMI, skeletal muscle index; SMA, skeletal muscle area; IGF-1, insulin-like growth factor-1. to its accuracy (21). However, few studies have used CT to evaluate the adipose tissue distribution and its correlation with prognosis in gastric cancer patients. Therefore, this study used CT to evaluate the preoperative adipose tissue distribution of patients with resectable gastric cancer and explored the relationship between adipose tissue distribution and long-term prognosis in gastric cancer.

\section{METHODS}

\section{Participants}

A total of 607 patients who underwent radical gastrectomy from January 2013 to December 2017 at HwaMei Hospital, University of Chinese Academy of Sciences, were included in this retrospective observational cohort study. The inclusion criteria were as follows: (1) histologically proven primary adenocarcinoma of the stomach; (2) no previous history of gastrectomy or other malignant tumors; (3) pathologically negative resection margins (R0 resection) and lymphadenectomy (D1 or more). Exclusion criteria include the following: (1) The patient had received neoadjuvant chemotherapy or chemoradiotherapy before surgery; (2) The patients had postoperative survival time less than 30 days; (3) Patients were followed up for less than 36 months. This study was approved by the Ethics Committee of the HwaMei Hospital, University of Chinese Academy of Sciences (approval NO. PJ-NBEY-KY-2019-15301 ). Written informed consent was obtained from all the participants.

\section{Histological Examination}

The surgical specimens were assessed according to the handling guideline of the 3rd edition of the Japanese classification of gastric carcinoma (22) and confirmed by three senior pathologists, specialists in gastric cancer. Routine pathology in the department of pathology included the use of pro forma reports and whole-mount slides. Information on pathological variables, including tumor location, differentiation, perineural invasion, lymph vascular invasion, and tumor size, were obtained from the histopathological reports. $\mathrm{T}$ and $\mathrm{N}$ stages were classified according to the 8th edition of the (Union for International Cancer Control/American Joint Committee on Cancer) UICC/ AJCC TNM staging system (23).

\section{Demographic and Clinical Parameters}

Demographic and clinical characteristics, including age, gender, gastrectomy, and postoperative chemotherapy, were retrieved within $24 \mathrm{~h}$ after hospitalization. Weight and height were 
measured with participants without shoes and were recorded to the nearest $0.1 \mathrm{~kg}$ and $0.1 \mathrm{~cm}$, respectively. BMI was calculated as body weight/height squared $\left(\mathrm{kg} / \mathrm{m}^{2}\right)$. In general, Asian populations have a smaller physique than Western individuals and tend to suffer from metabolic complications of obesity at a lower BMI than others, thus overweight/obese patients were defined as BMI $\geq 25 \mathrm{~kg} / \mathrm{m}^{2}$ in the present study (24).

\section{Measurement of Adipose Tissue Distribution Parameters}

CT images were taken within 15 days before surgical resection and then analyzed. The level of the third lumbar vertebra landmark was independently identified by two experienced radiologists. The corresponding single axial image was extracted and saved as a DICOM image file. ABACS Auto Segmentation module in SliceOmatic software (ver. 5.0) was used to measure the patient's adipose tissue distribution parameters, including the crosssectional area of VAT, SAT, and intramuscular adipose tissue (Figure 1). The total fat area was equal to the sum of VAT, SAT, and intramuscular adipose tissue areas. Percentages of VAT and SAT were calculated by dividing VAT area and SAT area divided by total fat area $\left(\mathrm{cm}^{2} / \mathrm{cm}^{2}\right)$, respectively. The VAT/SAT ratio was calculated by dividing the VAT area by SAT area.

\section{Follow-Up}

All patients were followed up every 3-6 months for the first 2 years and annually thereafter until death or at least 5 years after the surgery. Disease-specific survival (DSS) was defined as the time from surgery to death of gastric cancer. Cases in which patients were lost during follow-up or died of other diseases were regarded as censored, and the date of their last known contact was recorded. The median follow-up period for the present cohort was 50 months (range 3-95 months) and the follow-up was closed in December 2020.

\section{Statistical Analysis}

The characteristics of the patients are presented as median (interquartile range) for continuous variables and frequency (percentages) for categorical variables. The differences between overweight/obese and non-overweight/obese patients were tested using the Wilcoxon rank-sum test for continuous variables and chi-squared tests or Fisher's exact test for categorical variables. The optimal cutoff points for VAT and SAT percentages and VAT/SAT ratio were determined using maximally selected log-rank statistics [R packages (maxstat)]. The DSS rate was analyzed using the Kaplan-Meier method and the log-rank test was used to determine significant differences between groups. The association between overweight/obesity and DSS was examined using multiple Cox regression models after adjusting for age, gender, $\mathrm{T}$ stage, $\mathrm{N}$ stage, and chemotherapy. The relationships between adipose tissue distribution parameters, and DSS were analyzed after additionally adjusting for overweight/obesity. We further divided patients into three subgroups based on overweight/ obesity and VAT/SAT ratio categories: 1) Overweight/obese patients with low VAT/SAT ratio, 2) non-overweight/obese patient with low VAT/SAT ratio or overweight/obese patients with high VAT/SAT ratio, and 3) non-overweight/obese patient with high VAT/SAT ratio. The differences among these groups were tested using analyses of variance for continuous variables and chi-squared tests or Fisher's exact test for categorical variables. The multiple Cox regression model was reconducted to analyze the association between overweight/ obesity and VAT/SAT ratio categories and DSS. All p-values were two-tailed, and statistical significance was defined as $\mathrm{p}<0.05$. Statistical analyses were performed using STATA 15.1 .

\section{RESULTS}

\section{Patient Characteristics Based on Overweight/Obesity}

The baseline characteristics and classification of patients in the entire cohort are summarized in Table 1. Among the 607 patients, the number of male patients was more than twice that of female patients. The tumors in the distal stomach accounted
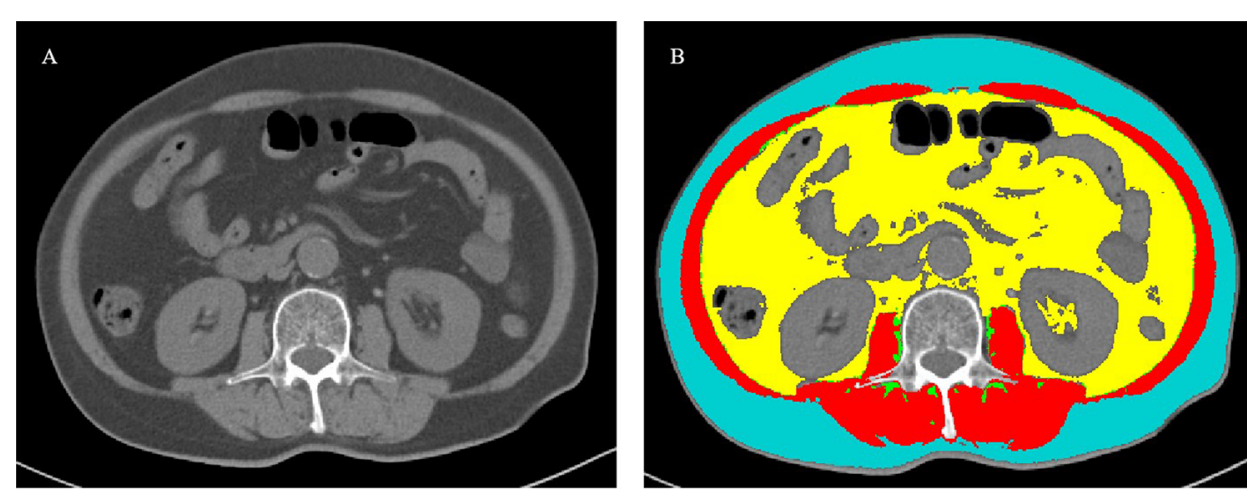

FIGURE 1 | Measurement of body composition parameters with cross-sectional CT images at the third lumbar level. (A) A cross-sectional CT image at the third lumbar level. (B) Body composition automatically calculated using the ABACS Auto Segmentation module in SliceOmatic software (ver. 5.0). Visceral adipose tissue, subcutaneous adipose tissue, intramuscular adipose tissue, and muscle were targeted as yellow, blue, green, and red, respectively. 
TABLE 1 | Characteristics of entire cohort and classified by overweight/obesity.

\begin{tabular}{|c|c|c|c|c|}
\hline & $\begin{array}{c}\text { Total } \\
(\mathrm{N}=607)\end{array}$ & $\begin{array}{l}\text { Overweight/obesity } \\
\qquad(N=114)\end{array}$ & $\begin{array}{l}\text { Non-overweight/obesity } \\
\text { ( } \mathrm{N}=493)\end{array}$ & $P$ value \\
\hline Age (>65 years) & $268(44.15)$ & $46(40.35)$ & 222 (45.03) & 0.365 \\
\hline Male & $428(70.51)$ & $77(67.54)$ & $351(71.20)$ & 0.441 \\
\hline BMI & $22.1(19.79,24.2)$ & $26.79(25.71,27.7)$ & $21.28(19.20,23.03)$ & $<0.001$ \\
\hline Tumor location & & & & 0.058 \\
\hline Upper third & $60(9.88)$ & $18(15.79)$ & $42(8.52)$ & \\
\hline Middle third & $78(12.85)$ & $12(10.53)$ & 66 (13.39) & \\
\hline Lower third & $461(75.95)$ & $84(73.68)$ & $377(76.47)$ & \\
\hline Two-thirds or more & $8(1.32)$ & $0(0.00)$ & $8(1.62)$ & \\
\hline Gastrectomy & & & & 0.541 \\
\hline Distal & $488(80.40)$ & $88(77.19)$ & $400(81.14)$ & \\
\hline Total & $118(19.44)$ & $26(22.81)$ & 92 (18.66) & \\
\hline Proximal & $1(0.16)$ & $0(0.00)$ & $1(0.20)$ & \\
\hline Tumor size (>5 cm) & $148(24.38)$ & $28(24.56)$ & $120(24.34)$ & 0.961 \\
\hline Differentiated & $313(51.57)$ & $66(57.89)$ & $247(50.10)$ & 0.133 \\
\hline Perineural invasion & 239 (39.37) & $47(41.23)$ & $192(38.95)$ & 0.653 \\
\hline Lymph vascular invasion & $283(46.62)$ & $55(48.25)$ & $228(46.25)$ & 0.700 \\
\hline T category & & & & 0.022 \\
\hline $\mathrm{T} 1$ & $171(28.17)$ & $31(27.19)$ & $140(28.40)$ & \\
\hline $\mathrm{T} 2$ & $72(11.86)$ & $12(10.53)$ & $60(12.17)$ & \\
\hline T3 & $12(1.98)$ & $6(5.26)$ & $6(1.22)$ & \\
\hline $\mathrm{T} 4 \mathrm{a}$ & $339(55.85)$ & $60(52.63)$ & $279(56.59)$ & \\
\hline $\mathrm{T} 4 \mathrm{~b}$ & $12(2.14)$ & $5(4.39)$ & $8(1.62)$ & \\
\hline $\mathrm{N}$ category & & & & 0.960 \\
\hline NO & $255(42.01)$ & $48(42.11)$ & 207 (41.99) & \\
\hline N1 & $94(15.49)$ & $18(15.79)$ & $76(15.42)$ & \\
\hline N2 & $120(19.77)$ & $20(17.54)$ & $100(20.28)$ & \\
\hline $\mathrm{N} 3 \mathrm{a}$ & $106(17.46)$ & $22(19.30)$ & $84(17.04)$ & \\
\hline N3b & $32(5.27)$ & $6(5.26)$ & $26(5.27)$ & \\
\hline Chemotherapy & $401(66.06)$ & $82(71.93)$ & $319(64.71)$ & 0.142 \\
\hline \multicolumn{5}{|c|}{ Adipose tissue distribution parameters } \\
\hline SAT area & $91.72(56.35,126.60)$ & $130.85(100.70,163.00)$ & $81.89(49.92,114.30)$ & $<0.001$ \\
\hline VAT area & $94.17(45.00,149.40)$ & $171.55(114.90,222.70)$ & $80.88(36.17,130.20)$ & $<0.001$ \\
\hline Total fat area & $205.47(118.86,292.48)$ & $321.52(261.11,286.37)$ & $183.53(99.90,252.02)$ & $<0.001$ \\
\hline SAT percent & $0.47(0.38,0.58)$ & $0.43(0.34,0.55)$ & $0.48(0.39,0.60)$ & 0.002 \\
\hline High SAT percent & $88(14.50)$ & $14(12.28)$ & $74(15.01)$ & 0.456 \\
\hline VAT percent & $0.47(0.35,0.58)$ & $0.55(0.43,0.63)$ & $0.46(0.33,0.56)$ & $<0.001$ \\
\hline High VAT percent & 505 (83.20) & $106(92.98)$ & 399 (80.93) & 0.002 \\
\hline VAT/SAT ratio & $1.01(0.60,1.50)$ & $1.27(0.79,1.83)$ & $0.96(0.56,1.44)$ & $<0.001$ \\
\hline High VAT/SAT ratio & $529(87.15)$ & $108(94.74)$ & $421(85.40)$ & 0.007 \\
\hline
\end{tabular}

BMI, body mass index; SAT, subcutaneous adipose tissue; VAT, visceral adipose tissue.

$P$ value for difference between groups in percentages (chi-square test or Fisher's exact test) or rank sum (Kruskal-Wallis test).

Bold values represent statistically significant differences $(P<0.05)$.

for $80 \%$ of all the tumors. Patients with gastric cancer stages I, II, and III were 197, 112, and 298, respectively. The 5-year diseasespecific survival rates of patients in the present study was $79.9 \%$, and were $97.6,86.1$, and $68.0 \%$ for patients in stages I, II, and III, respectively (data not shown).

There were no significant differences in demographic and clinical parameters except for $\mathrm{T}$ staging distribution between overweight/obesity groups. Compared with non-overweight/ obese patients, overweight/obese patients had a low SAT percentage $(\mathrm{p}=0.002)$, high VAT percentage $(\mathrm{p}<0.001)$, and high VAT/SAT ratio $(\mathrm{p}<0.001)$.

\section{Overweight/Obesity and DSS}

The optimal cutoff values of SAT percentage, VAT percentage, and VAT/SAT ratio were 64,30 , and $44 \%$, respectively (Figure S1).
Kaplan-Meier curves of DSS based on overweight/obesity are shown in Figure 2. Compared with non-overweight/obese patients, overweight/obese patients had a significantly better prognosis $(\mathrm{p}=0.009)$. Furthermore, a multiple Cox regression model was conducted to examine the relationship between overweight/obesity and DSS (Table 2). After adjusting for age, gender, T categories, $\mathrm{N}$ categories, and chemotherapy, overweight/ obesity was an independent protective factor for long-term DSS in gastric cancer patients $(\mathrm{HR}=0.61,95 \% \mathrm{CI}: 0.37-0.99)$.

\section{Adipose Tissue Distribution and DSS}

Kaplan-Meier curves of DSS based on adipose tissue distribution, including SAT and VAT percentages and VAT/SAT ratio are shown in Figure 3. Compared with patients with a low VAT/SAT ratio, patients with a high VAT/SAT ratio had a significantly worse prognosis $(p=0.049)$. Multiple Cox regression models were 


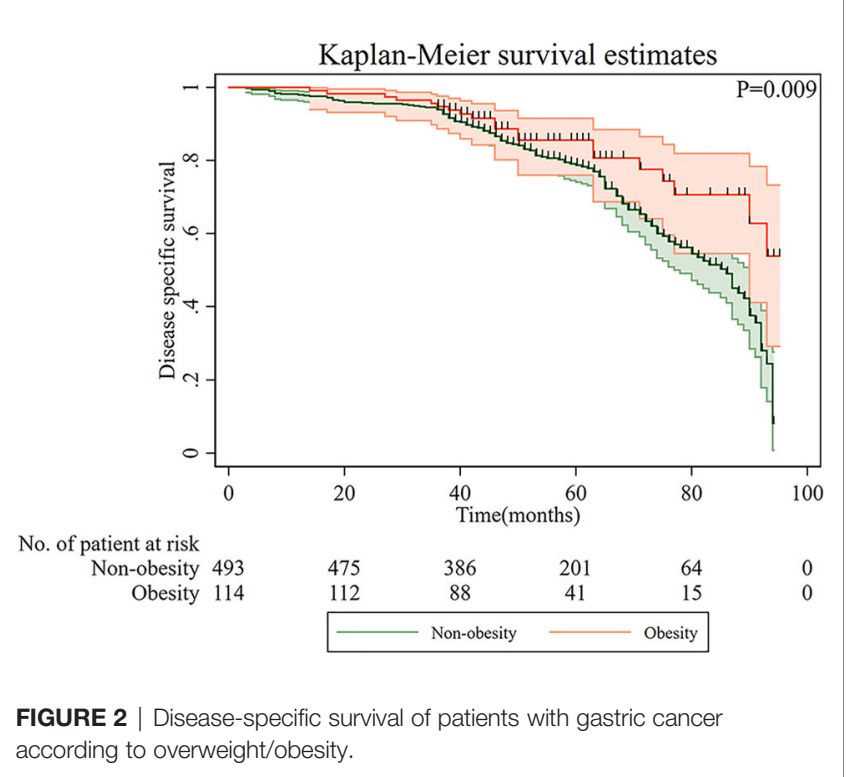

TABLE 2 | Association between overweight/obesity and disease-specific survival by multivariate Cox analysis in patients with gastric cancer.

\begin{tabular}{lcr}
\hline & HR $(\mathbf{9 5} \% \mathbf{C l})$ & P value \\
\hline Overweight/obesity & $0.61(0.37,0.99)$ & $\mathbf{0 . 0 4 4}$ \\
Age (>65 years) & $1.59(1.14,2.2)$ & $\mathbf{0 . 0 0 6}$ \\
Female & $0.89(0.63,1.26)$ & 0.506 \\
T category & & \\
T1 & & \\
T2 & $2.51(0.88,7.15)$ & 0.084 \\
T3 & $2.97(0.57,15.55)$ & 0.197 \\
T4a & $3.81(1.54,9.42)$ & $\mathbf{0 . 0 0 4}$ \\
T4b & $10.76(3.47,33.33)$ & $<\mathbf{0 . 0 0 1}$ \\
N category & & \\
N0 & & \\
N1 & $2.34(1.19,4.63)$ & $\mathbf{0 . 0 1 4}$ \\
N2 & $2.33(1.24,4.38)$ & $\mathbf{0 . 0 0 9}$ \\
N3a & $6.24(3.37,11.55)$ & $<\mathbf{0 . 0 0 1}$ \\
N3b & $8.28(4.12,16.62)$ & $\mathbf{0 . 0 0 1}$ \\
Chemotherapy & $0.80(0.53,1.21)$ & 0.294 \\
\hline
\end{tabular}

$B M I$, body mass index; $H R$, hazard ratios; $\mathrm{Cl}$, confidence interval.

Bold values represent statistically significant differences $(P<0.05)$.

conducted to evaluate the relationship between adipose tissue distribution parameters and DSS (Table 3). After additionally adjusting for overweight/obesity, high SAT percentage was an independent protective factor ( $\mathrm{HR}=0.59,95 \% \mathrm{CI}$ : 0.36-0.96), while high VAT percentage (HR $=1.68,95 \%$ CI: $1.06-2.68)$ and high VAT/SAT ratio (HR $=1.99,95 \%$ CI: $1.19-3.34)$ were independent risk factors for DSS of gastric cancer.

\section{Overweight/Obesity and VAT/SAT Categories and DSS}

The patients were subclassified into three subgroups based on overweight/obesity and VAT/SAT categories. The characteristics of patients of each group are shown in Table 4. Compared with patients in the non-overweight/obesity with high VAT/SAT ratio group, most patients in the overweight/obesity with low VAT/SAT ratio were female and younger. Kaplan-Meier curves of DSS based on overweight/obesity and VAT/SAT categories are shown in Figure 4. There was a significant difference in DSS among the overweight/obesity and VAT/SAT categories groups $(\mathrm{p}=0.003)$. Multiple Cox regression models were performed to explore the relationship between overweight/obesity and VAT/SAT categories and DSS (Table 5). Compared with patients in the other two groups, patients in the non-overweight/obesity with high VAT/SAT ratio group had a worse prognosis ( $\mathrm{HR}=1.89,95 \% \mathrm{CI}$ : 1.28-2.77).

\section{DISCUSSION}

In the present study, we observed that in addition to the wellestablished $\mathrm{T}$ and $\mathrm{N}$ stages, $\mathrm{BMI}$ was an independent risk factor for the prognosis of resectable gastric cancer. The result showed overweight/obesity was a predictive factor for the prognosis of patients with gastric cancer. Subsequently, the adipose tissue distribution analysis showed that VAT was negatively correlated with the prognosis of gastric cancer, while SAT was protective correlated with the prognosis of gastric cancer. Moreover, the VAT/ SAT ratio was an independent risk factor for the prognosis of gastric cancer. To the best of our knowledge, this is the first study documenting how different types of body adipose tissue distribution differentially influence the prognosis of patients with gastric cancer.

Meanwhile, our study showed that overweight/obese patients (BMI $\geq 25 \mathrm{~kg} / \mathrm{m}^{2}$ ) had a better prognosis than non-overweight/ obese patients (BMI $<25 \mathrm{~kg} / \mathrm{m}^{2}$ ) with gastric cancer. This phenomenon has been reported in some previous studies, although the sample size was small in those retrospective studies (25). However, a randomized controlled trial from Korea demonstrated that BMI was not associated with the prognosis of gastric cancer (26). Only 136 patients were included in the trial, including 27 obese cases, and the small sample size may be one of the reasons for the lack of statistically significant difference in the results. Meanwhile, Rodrigues reported that obesity was not associated with gastric cancer prognosis in the Western population, although the obesity threshold was BMI $=30 \mathrm{~kg} / \mathrm{m}^{2}$ in the study (7). It is noteworthy that there are several differences in the study of gastric cancer between Eastern and Western countries. Firstly, compared with Western countries, Asian countries had a high incidence of gastric cancer, especially in China (27). Secondly, in Rodrigues' study, obese gastric cancer patients in China accounted for less than $20 \%$ of the total number of cases, but over $60 \%$ accounted for Western obese gastric cancer patients, which may be the reason for the inconsistent results (7). Obese patients also have better physical and nutritional status than non-obese patients $(28,29)$. As a result, obese patients are more likely to receive adjuvant treatment, including chemotherapy, which may improve prognosis.

Although obesity (BMI $\geq 30 \mathrm{~kg} / \mathrm{m}^{2}$ ) and overweight (BMI, 25$30 \mathrm{~kg} / \mathrm{m}^{2}$ ) are not suitable for combined analysis, because the former is a real disease and the latter is only a risk factor. However, overweight and obesity were studied together in this study for two reasons. On the one hand, obesity accounts for a relatively small proportion of gastric cancer in Asian population. In this study, there were only seven obese patients. On the 

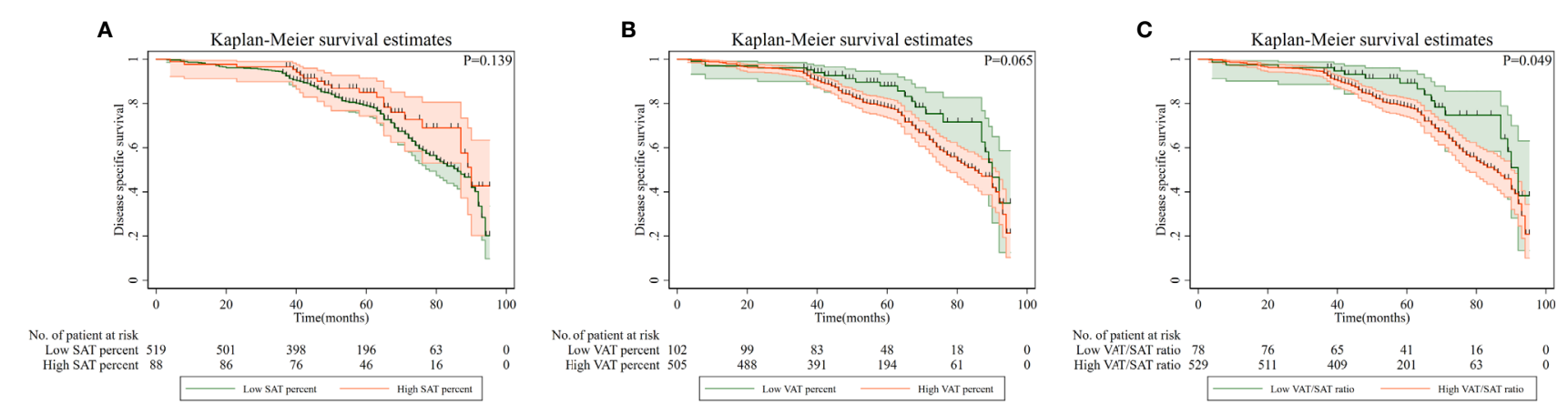

FIGURE 3 | Disease-specific survival of patients with gastric cancer according to adipose tissue distribution parameters. (A) High SAT percentage; (B) High VAT percentage; (C) High SATNAT ratio. VAT, visceral adipose tissue; SAT, subcutaneous adipose tissue.

TABLE 3 | Associations between adipose tissue distribution parameters and disease-specific survival by multivariate Cox analysis in patients with gastric cancer.

\begin{tabular}{|c|c|c|c|c|c|c|}
\hline & \multicolumn{2}{|c|}{ High SAT percent } & \multicolumn{2}{|c|}{ High VAT percent } & \multicolumn{2}{|c|}{ VAT/SAT ratio } \\
\hline & HR $(95 \% \mathrm{Cl})$ & $P$ value & HR $(95 \% \mathrm{Cl})$ & $P$ value & HR $(95 \% \mathrm{Cl})$ & $P$ value \\
\hline Adipose tissue distribution parameter & $0.59(0.36,0.96)$ & 0.032 & $1.68(1.06,2.68)$ & 0.028 & $1.99(1.19,3.34)$ & 0.009 \\
\hline Overweight/obesity & $0.56(0.34,0.91)$ & 0.021 & $0.55(0.34,0.91)$ & 0.019 & $0.55(0.33,0.90)$ & 0.017 \\
\hline Age (>65 years) & $1.56(1.13,2.17)$ & 0.008 & $1.54(1.11,2.14)$ & 0.010 & $1.56(1.12,2.16)$ & 0.008 \\
\hline Female & $0.98(0.69,1.4)$ & 0.929 & $0.93(0.66,1.32)$ & 0.696 & $0.95(0.67,1.35)$ & 0.794 \\
\hline \multicolumn{7}{|l|}{ T category } \\
\hline T1 & 1 & & 1 & & 1 & \\
\hline $\mathrm{T} 2$ & $2.51(0.88,7.13)$ & 0.085 & $2.49(0.87,7.08)$ & 0.880 & $2.49(0.88,7.07)$ & 0.087 \\
\hline T3 & $2.77(0.52,14.66)$ & 0.230 & $2.86(0.54,15.09)$ & 0.216 & $2.81(0.53,14.77)$ & 0.223 \\
\hline $\mathrm{T} 4 \mathrm{a}$ & $3.59(1.45,8.88)$ & 0.006 & $3.61(1.46,8.95)$ & 0.006 & $3.63(1.47,8.95)$ & 0.005 \\
\hline $\mathrm{T} 4 \mathrm{~b}$ & $10.44(3.35,32.47)$ & $<0.001$ & $10.39(3.34,32.31)$ & $<0.001$ & $10.73(3.47,33.20)$ & $<0.001$ \\
\hline \multicolumn{7}{|l|}{$\mathrm{N}$ category } \\
\hline NO & 1 & & 1 & & 1 & \\
\hline N1 & $2.38(1.21,4.68)$ & 0.012 & $2.31(1.17,4.57)$ & 0.016 & $2.33(1.18,4.60)$ & 0.015 \\
\hline N2 & $2.45(1.3,4.61)$ & 0.005 & $2.35(1.25,4.43)$ & 0.008 & $2.42(1.29,4.54)$ & 0.006 \\
\hline N3a & $6.74(3.63,12.51)$ & $<0.001$ & $6.55(3.53,12.14)$ & $<0.001$ & $6.65(3.60,12.30)$ & $<0.001$ \\
\hline N3b & $9.01(4.47,18.15)$ & $<0.001$ & $8.65(4.3,17.4)$ & $<0.001$ & $8.96(4.46,18.01)$ & $<0.001$ \\
\hline Chemotherapy & $0.82(0.54,1.25)$ & 0.356 & $0.81(0.54,1.23)$ & 0.329 & $0.82(0.54,1.24)$ & 0.340 \\
\hline
\end{tabular}

BMI, body mass index; SAT, subcutaneous adipose tissue; VAT, visceral adipose tissue; HR, hazard ratios; Cl, confidence interval.

Bold values represent statistically significant differences $(P<0.05)$.

other hand, the target population was further divided into obese and overweight groups for subgroup analysis, and the trend obtained was consistent with the current results (Table S1). Therefore, obese and overweight patients were combined. In addition, skeletal muscle index (SMI) was analyzed, which is the ratio between skeletal muscle area (SMA) and height squared. In univariate analysis, $\mathrm{HR}=1.024(0.744,1.409) ; \mathrm{p}=0.884$, SMI was not associated with the prognosis of gastric cancer.

Obese patients may also have tumors that are sensitive to chemotherapy. Campbell et al. found that overweight and obese patients were more likely to have microsatellite instability-stable and low-microsatellite instability tumors than normal-weight patients in colorectal cancer (30). Evidence suggests that microsatellite instability-stable and low-microsatellite instability tumors are more susceptible to fluorouracil treatment than high-microsatellite instability tumors (31). This information may support the protective effect observed in overweight/obese patients. Therefore, the effect of obesity on cancer is complex and seemingly paradoxical.
Most studies may use BMI to define overweight/obesity, which does not reflect adipose tissue distribution.

We further investigated the correlation between adipose tissue distribution and the prognosis of gastric cancer. The adipose tissue distribution was still associated with gastric cancer prognosis after adjusting for BMI. Consistent with our results, previous reports have shown the negative effect of visceral fat on the prognosis of cancer patients $(11,19)$. Similarly, Dong et al. included over 1,000 cases of gastric cancer and showed that low subcutaneous fat was a risk factor for the prognosis of gastric cancer, including overall survival and disease-free survival (32). However, some studies have suggested that visceral fat is not associated with the prognosis of gastrointestinal tumors. These studies had a sample size of less than 100 and most patients had received neoadjuvant chemotherapy (33-35). Neoadjuvant chemotherapy may affect the judgment of the influence of adipose tissue on the prognosis of gastric cancer. Besides, it is well known that TNM staging is the most important tool for 
TABLE 4 | Characteristics of entire cohort and classified by overweight/obesity and VAT/SAT ratio.

\begin{tabular}{|c|c|c|c|c|}
\hline & $\begin{array}{l}\text { Overweight/ } \\
\text { obesity with } \\
\text { low VAT/ } \\
\text { SAT ratio } \\
\text { (N = 6) }\end{array}$ & $\begin{array}{l}\text { Non- } \\
\text { overweight/ } \\
\text { obesity or high } \\
\text { VAT/SAT ratio } \\
\text { (N = 180) }\end{array}$ & $\begin{array}{c}\text { Non- } \\
\text { overweight/ } \\
\text { obesity with } \\
\text { high VAT/SAT } \\
\text { ratio } \\
(\mathrm{N}=421)\end{array}$ & $\begin{array}{c}P \\
\text { value }\end{array}$ \\
\hline Age (>65 years) & $1(16.67)$ & $65(36.11)$ & 202 (47.98) & 0.008 \\
\hline Female & 5 (83.33) & $74(41.11)$ & $100(23.75)$ & $<0.001$ \\
\hline Tumor location & & & & 0.283 \\
\hline Upper third & $0(0)$ & 24 (13.33) & $36(8.55)$ & \\
\hline Middle third & 2 (33.33) & 21 (11.67) & 55 (13.06) & \\
\hline Lower third & $4(66.67)$ & $134(74.44)$ & 323 (76.72) & \\
\hline $\begin{array}{l}\text { Two-thirds or } \\
\text { more }\end{array}$ & $0(0)$ & $1(0.56)$ & $7(1.66)$ & \\
\hline Gastrectomy & & & & 0.863 \\
\hline Distal & 5 (83.33) & 142 (78.89) & $341(81)$ & \\
\hline Total & $1(16.67)$ & $38(21.11)$ & 79 (18.76) & \\
\hline Proximal & $0(0)$ & $0(0)$ & $1(0.24)$ & \\
\hline $\begin{array}{l}\text { Tumor size } \\
(>5 \mathrm{~cm})\end{array}$ & $1(16.67)$ & 43 (23.89) & $104(24.7)$ & 0.970 \\
\hline Differentiated & $4(66.67)$ & $101(56.11)$ & 208 (49.41) & 0.252 \\
\hline Perineural invasion & $3(50.0)$ & 69 (38.33) & 167 (39.67) & 0.791 \\
\hline $\begin{array}{l}\text { Lymph vascular } \\
\text { invasion }\end{array}$ & $4(66.67)$ & $80(44.44)$ & 199 (47.27) & 0.493 \\
\hline T category & & & & 0.304 \\
\hline $\mathrm{T} 1$ & 2 (33.33) & $54(30.0)$ & 115 (27.32) & \\
\hline $\mathrm{T} 2$ & $1(16.67)$ & $20(11.11)$ & $51(12.11)$ & \\
\hline T3 & $0(0)$ & 7 (3.89) & $5(1.19)$ & \\
\hline $\mathrm{T} 4 \mathrm{a}$ & $3(50.0)$ & $93(51.67)$ & $243(57.72)$ & \\
\hline $\mathrm{T} 4 \mathrm{~b}$ & $0(0)$ & $6(3.33)$ & $7(1.66)$ & \\
\hline $\mathrm{N}$ category & & & & 0.340 \\
\hline NO & $4(66.67)$ & 78 (43.33) & 173 (41.09) & \\
\hline N1 & $0(0)$ & $26(14.44)$ & $68(16.15)$ & \\
\hline N2 & 2 (33.33) & 27 (15.0) & 91 (21.62) & \\
\hline N3a & $0(0)$ & 39 (21.67) & 67 (15.91) & \\
\hline N3b & $0(0)$ & $10(5.56)$ & $22(5.23)$ & \\
\hline Chemotherapy & $3(50.0)$ & 124 (68.89) & 274 (65.08) & 0.428 \\
\hline
\end{tabular}

SAT, subcutaneous adipose tissue; VAT, visceral adipose tissue.

$P$ value for difference among three groups in percentages (chi-square test or Fisher's exact test) or rank sum (Kruskal-Wallis test).

Bold values represent statistically significant differences $(P<0.05)$.

prognostic stratification in gastric cancer. The TNM stage (ypTNM stage) of the patients after neoadjuvant therapy and the TNM stage (pTNM stage) of the patients who did not receive neoadjuvant therapy are not suitable to be combined for analysis, because the predictive value of the two for prognosis is inconsistent. Therefore, gastric cancer patients receiving neoadjuvant chemotherapy were not included in this study. Similarly, an observational study of 447 gastrointestinal tumors showed that pretreatment of subcutaneous adiposity was not associated with the prognosis of esophageal and gastric cancer (36). The study was limited in that it included only 65 cases of gastric cancer and did not perform a subgroup analysis of gastric cancer patients. A randomized controlled trial showed that preoperative visceral fat and subcutaneous fat areas were not associated with the prognosis of gastric cancer, although it had a small sample size (26). Conversely, Feng believed that low visceral fat was an independent risk factor for the prognosis of gastric cancer; however, only 46 cases of metastatic gastric cancer

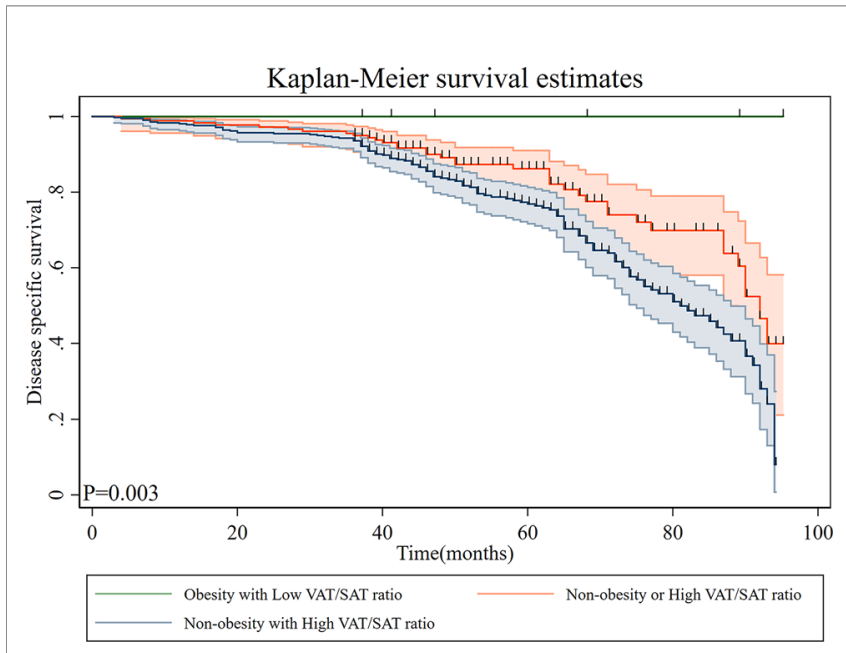

FIGURE 4 | Disease-specific survival of patients with gastric cancer according to overweight/obesity and VAT/SAT ratio category. VAT, visceral adipose tissue; SAT, subcutaneous adipose tissue.

TABLE 5 | Association between non-overweight/obesity with high VAT/SAT ratio and disease-specific survival by multivariate Cox analysis in patients with gastric cancer.

\begin{tabular}{lcc}
\hline & HR $(\mathbf{9 5 \%} \mathbf{C l})$ & P value \\
\hline Non-overweight/obesity with high VAT/SAT ratio & $1.89(1.28,2.77)$ & $\mathbf{0 . 0 0 1}$ \\
Age (>65 years) & $1.57(1.13,2.17)$ & $\mathbf{0 . 0 0 7}$ \\
Female & $0.95(0.67,1.34)$ & 0.755 \\
T category & & \\
T1 & 1 & \\
T2 & $2.44(0.86,6.94)$ & 0.094 \\
T3 & $2.88(0.56,14.93)$ & 0.208 \\
T4a & $3.64(1.48,8.97)$ & $\mathbf{0 . 0 0 5}$ \\
T4b & $10.78(3.48,33.36)$ & $<\mathbf{0 . 0 0 1}$ \\
N category & 1 & \\
N0 & $2.33(1.18,4.60)$ & $\mathbf{0 . 0 1 5}$ \\
N1 & $2.38(1.27,4.47)$ & $\mathbf{0 . 0 0 7}$ \\
N2 & $6.62(3.58,12.24)$ & $<\mathbf{0 . 0 0 1}$ \\
N3a & $8.93(4.44,17.94)$ & $<\mathbf{0 . 0 0 1}$ \\
N3b & $0.82(0.54,1.24)$ & 0.351 \\
Chemotherapy (Yes) & & \\
\hline
\end{tabular}

SAT, subcutaneous adipose tissue; VAT, visceral adipose tissue; HR, hazard ratios; CI, confidence interval.

Bold values represent statistically significant differences $(P<0.05)$.

patients without surgery were included in the study (25). Therefore, these conclusions warrant further investigation.

VAT is an important metabolic tissue that secretes factors that systemically alter the immunologic, metabolic, and endocrine milieu. Excess VAT promotes chronic systemic inflammation with associated insulin resistance and dysmetabolism (37). Therefore, we further analyzed VAT and inflammatory markers, and the results showed that there was an association between the two. However, there was still a correlation between VAT and the prognosis of gastric cancer after adjusting inflammatory markers, suggesting that there could be other mechanisms by which VAT affects the prognosis of gastric cancer.

Furthermore, early studies suggested that patients with differentiated early gastric cancer had higher subcutaneous fat 
and visceral fat content than those with undifferentiated early gastric cancer and the researchers speculated that lower fat content was conducive to the occurrence and development of undifferentiated gastric cancer (38). Recently, visceral fat has been implicated in the promotion of carcinogenesis and cancer progression through several pathways, including adipocytokinerelated inflammation and insulin resistance. The latter is associated with disturbances in insulin-like growth factor-1 (IGF-1) and hypoxia (39). Adipocytokines secreted by visceral adiposity attract inflammatory cells, particularly macrophages and $\mathrm{T}$ cells, which produce cytokines, such as the tumor necrosis factor- $\alpha$ and interleukin- 6 , thereby creating a proinflammatory, insulin-resistant, protumorigenic environment. Excess visceral fat decreases adiponectin. Adiponectin inhibits the proliferation, angiogenesis, and inflammatory properties of tumor cells and promotes their apoptosis (40). It also induces chronic hyperinsulinemia followed by insulin resistance, which reduces the expression of IGF-binding protein, subsequently increasing IGF-1 expression. IGF-1 has protumorigenic properties and is linked to increased malignancy and progression of several gastrointestinal malignancies (41).

Other studies reported that the VAT/SAT ratio is associated with surgical site infections in patients with gastric cancer (42). Subcutaneous fat is associated with a postoperative incisional hernia for gastric cancer (43). Higher visceral fat was associated with higher postoperative complications of gastric cancer (44). However, there is growing evidence that postoperative complications are associated with the long-term prognosis of gastric cancer. A possible explanation is that cell-mediated immunity is compromised by surgical stress and excessive catecholamine and prostaglandin responses adversely affect the immune system, contributing to metastatic progression and worse survival outcomes (45).

Finally, we grouped patients with resectable gastric cancer using the VAT/SAT ratio and BMI as stratification factors. The results showed that overweight/obese patients with a low VAT/SAT ratio had the best prognosis, although only six cases were involved. In contrast, non-overweight/obese patients with a high VAT/SAT ratio had the worst prognosis. The latter accounted for the highest percentage of the entire cohort. Therefore, we believe that besides BMI, the adipose tissue distribution should also be considered during preoperative evaluation of gastric cancer patients.

This study comprehensively elaborated on the influence of different adipose tissue distributions on the prognosis of gastric cancer. We believe that BMI is a prognostic factor, and VAT and SAT have different effects on the prognosis of gastric cancer. However, this study has some shortcomings. First, we did not subdivide overweight/obese patients into subgroups according to severity of obesity, such as super-obese patients. However, super obesity is rare in patients with gastric cancer, especially in Asian populations. Secondly, because data on changes in adipose tissue distribution after surgery are not available, we did not analyze the changes in adipose tissue distribution after surgery and their association with prognosis, which merit further exploration. Finally, due to the initial stage of relevant research, the threshold value was not uniformly standardized. However, our method to establish an optimal cutoff value is adopted by most of the current studies. Further research is warranted to verify our conclusions.

\section{CONCLUSIONS}

Prognostic factors for resectable gastric cancer include overweight/obesity. Further, VAT and SAT have different effects on the prognosis of gastric cancer. Our results showed that overweight/obesity is a protective factor for the prognosis of gastric cancer. The VAT/SAT ratio could be a promising prognostic factor for gastric cancer. Therefore, in preoperative evaluation of gastric cancer patients, attention should be paid not only to BMI but also to adipose tissue distribution.

\section{DATA AVAILABILITY STATEMENT}

The raw data supporting the conclusions of this article will be made available by the authors, without undue reservation.

\section{ETHICS STATEMENT}

Written informed consent was obtained from the individual(s) for the publication of any potentially identifiable images or data included in this article.

\section{AUTHOR CONTRIBUTIONS}

LG and YZ conceived and contributed to design of the study. JH, BX and LY collected and analyzed the data. KY and JZha analyzed and interpreted the data. PC, JZhe and JL supervised and contributed to writing the manuscript. All authors contributed to the article and approved the submitted version.

\section{FUNDING}

This study was funded by the Key Laboratory of Diagnosis and Treatment of Digestive System Tumors of Zhejiang Province (Grant No. 2019E10020), Ningbo Clinical Research Center for Digestive System Tumors (Grant No. 2019A21003) and Ningbo Municipal Non-Profit Fund for Applied Research (Grant No. 2019F1033).

\section{SUPPLEMENTARY MATERIAL}

The Supplementary Material for this article can be found online at: https://www.frontiersin.org/articles/10.3389/fonc.2021. 680190/full\#supplementary-material

Supplementary Figure 1 | Optimal cutoff values of adipose tissue distribution parameters. (A) SAT percentage; (B) VAT percentage; (C) VAT/SAT ratio. VAT, visceral adipose tissue; SAT, subcutaneous adipose tissue. 


\section{REFERENCES}

1. Sung H, Ferlay J, Siegel RL. Global Cancer Statistics 2020. GLOBOCAN Estimates of Incidence and Mortality Worldwide for 36 Cancers in 185 Countries. CA Cancer J Clin (2021) 71(3):209-49. doi: 10.3322/caac.21660

2. Songun I, Putter H, Kranenbarg EM, Sasako M, van de Velde CJ. Surgical Treatment of Gastric Cancer: 15-Year Follow-Up Results of the Randomised Nationwide Dutch D1D2 Trial. Lancet Oncol (2010) 11(5):439-49. doi: 10.1016/S1470-2045(10)70070-X

3. Macdonald JS, Smalley SR, Benedetti J, Hundahl SA, Estes NC, Stemmermann GN, et al. Chemoradiotherapy After Surgery Compared With Surgery Alone for Adenocarcinoma of the Stomach or Gastroesophageal Junction. N Engl J Med (2001) 345(10):725-30. doi: 10.1056/NEJMoa010187

4. Shimada S, Sawada N, Ishiyama Y, Nakahara K, Maeda C, Mukai S, et al. Impact of Obesity on Short- and Long-Term Outcomes of Laparoscopy Assisted Distal Gastrectomy for Gastric Cancer. Surg Endosc (2018) 32 (1):358-66. doi: 10.1007/s00464-017-5684-9

5. Sánchez Y, Vaca-Paniagua F, Herrera L, Oñate L, Herrera-Goepfert R, Navarro-Martínez G, et al. Nutritional Indexes as Predictors of Survival and Their Genomic Implications in Gastric Cancer Patients. Nutr Cancer (2020) 25:1-11. doi: 10.1080/01635581.2020.1797833

6. Jun DH, Kim BJ, Park JH, Kim JG, Chi KC, Park JM, et al. Preoperative Body Mass Index May Determine the Prognosis of Advanced Gastric Cancer. Nutr Cancer (2016) 68(8):1295-300. doi: 10.1080/01635581.2016.1224363

7. Rodrigues V, Landi F, Castro S, Mast R, Rodríguez N, Gantxegi A, et al. Is Sarcopenic Obesity an Indicator of Poor Prognosis in Gastric Cancer Surgery? A Cohort Study in a Western Population. J Gastrointest Surg (2020) 25 (6):1388-403. doi: 10.1007/s11605-020-04716-1

8. Zhao LL, Huang H, Wang Y, Wang TB, Zhou H, Ma FH, et al. Lifestyle Factors and Long-Term Survival of Gastric Cancer Patients: A Large Bidirectional Cohort Study From China. World J Gastroenterol (2020) 26 (14):1613-27. doi: 10.3748/wjg.v26.i14.1613

9. Struecker B, Biebl M, Dadras M, Chopra S, Denecke C, Spenke J, et al. The Impact of Obesity on Outcomes Following Resection for Gastric Cancer. Dig Surg (2017) 34(2):133-41. doi: 10.1159/000449043

10. Li XT, Tang L, Chen Y, Li YL, Zhang XP, Sun YS. Visceral and Subcutaneous Fat as New Independent Predictive Factors of Survival in Locally Advanced Gastric Carcinoma Patients Treated With Neo-Adjuvant Chemotherapy. J Cancer Res Clin Oncol (2015) 141(7):1237-47. doi: 10.1007/s00432-0141893-y

11. Okumura S, Kaido T, Hamaguchi Y, Kobayashi A, Shirai H, Yao S, et al. Visceral Adiposity and Sarcopenic Visceral Obesity Are Associated With Poor Prognosis After Resection of Pancreatic Cancer. Ann Surg Oncol (2017) 24 (12):3732-40. doi: 10.1245/s10434-017-6077-y

12. Rickles AS, Iannuzzi JC, Mironov O, Deeb AP, Sharma A, Fleming FJ, et al. Visceral Obesity and Colorectal Cancer: Are We Missing the Boat With BMI? J Gastrointest Surg (2013) 17(1):133-43; discussion p.143. doi: 10.1007/ s11605-012-2045-9

13. Brown JC, Caan BJ, Prado CM, Cespedes Feliciano EM, Xiao J, Kroenke CH, et al. The Association of Abdominal Adiposity With Mortality in Patients With Stage I-III Colorectal Cancer. J Natl Cancer Inst (2020) 112(4):377-83. doi: 10.1093/jnci/djz150

14. Antoun S, Bayar A, Ileana E, Laplanche A, Fizazi K, di Palma M, et al. High Subcutaneous Adipose Tissue Predicts the Prognosis in Metastatic CastrationResistant Prostate Cancer Patients in Post Chemotherapy Setting. Eur J Cancer (2015) 51(17):2570-7. doi: 10.1016/j.ejca.2015.07.042

15. Pai PC, Chuang CC, Chuang WC, Tsang NM. Pretreatment Subcutaneous Adipose Tissue Predicts the Outcomes of Patients With Head and Neck Cancer Receiving Definitive Radiation and Chemoradiation in Taiwan. Cancer Med (2018) 7(5):1630-41. doi: 10.1002/cam4.1365

16. Kobayashi T, Kawai H, Nakano O, Abe S, Kamimura H, Sakamaki A, et al. Prognostic Value of Subcutaneous Adipose Tissue Volume in Hepatocellular Carcinoma Treated With Transcatheter Intra-Arterial Therapy. Cancer Manag Res (2018) 10:2231-9. doi: 10.2147/CMAR.S167417

17. Silva A, Faria G, Araújo A, Monteiro MP. Impact of Adiposity on Staging and Prognosis of Colorectal Cancer. Crit Rev Oncol Hematol (2020) 145:102857. doi: 10.1016/j.critrevonc.2019.102857
18. Xiao J, Mazurak VC, Olobatuyi TA, Caan BJ, Prado CM. Visceral Adiposity and Cancer Survival: A Review of Imaging Studies. Eur J Cancer Care (2018) 27(2):e12611. doi: 10.1111/ecc.12611

19. Kim B, Chung MJ, Park SW, Park JY, Bang S, Park SW, et al. Visceral Obesity Is Associated With Poor Prognosis in Pancreatic Adenocarcinoma. Nutr Cancer (2016) 68(2):201-7. doi: 10.1080/01635581.2016.1134600

20. Lee JW, Son MW, Chung IK, Cho YS, Lee MS, Lee SM. Significance of CT Attenuation and F-18 Fluorodeoxyglucose Uptake of Visceral Adipose Tissue for Predicting Survival in Gastric Cancer Patients After Curative Surgical Resection. Gastric Cancer (2020) 23(2):273-84. doi: 10.1007/s10120-019-01001-2

21. Cakir H, Heus C, van der Ploeg TJ, Houdijk AP. Visceral Obesity Determined by CT Scan and Outcomes After Colorectal Surgery; a Systematic Review and Meta-Analysis. Int J Colorectal Dis (2015) 30(7):875-82. doi: 10.1007/s00384015-2174-1

22. Japanese Gastric Cancer Association. Japanese Classification of Gastric Carcinoma: 3rd English Edition. Gastric Cancer (2011) 14(2):101-12. doi: 10.1007/s10120-011-0041-5

23. He X, Wu W, Lin Z, Ding Y, Si J, Sun LM. Validation of the American Joint Committee on Cancer (AJCC) 8th Edition Stage System for Gastric Cancer Patients: A Population-Based Analysis. Gastric Cancer (2017) 142(2):391-400. doi: 10.1007/s10120-017-0770-1

24. Feng H, Wang X, Zhao T, Mao L, Hui Y, Fan X, et al. Myopenic Obesity Determined by Visceral Fat Area Strongly Predicts Long-Term Mortality in Cirrhosis. Clin Nutr (2021) 40(4):1983-9. doi: 10.1016/j.clnu.2020.09.016

25. Feng W, Huang M, Zhao X, Chen S, Wang C, Chang J, et al. Severe Loss of Visceral Fat and Skeletal Muscle After Chemotherapy Predicts Poor Prognosis in Metastatic Gastric Cancer Patients Without Gastrectomy. J Cancer (2020) 11(11):3310-7. doi: 10.7150/jca.37270

26. Park HS, Kim HS, Beom SH, Rha SY, Chung HC, Kim JH, et al. Marked Loss of Muscle, Visceral Fat, or Subcutaneous Fat After Gastrectomy Predicts Poor Survival in Advanced Gastric Cancer: Single-Center Study From the CLASSIC Trial. Ann Surg Oncol (2018) 25(11):3222-30. doi: 10.1245/s10434018-6624-1

27. Quach DT, Hiyama T, Gotoda T. Identifying High-Risk Individuals for Gastric Cancer Surveillance From Western and Eastern Perspectives: Lessons to Learn and Possibility to Develop an Integrated Approach for Daily Practice. World J Gastroenterol (2019) 25(27):3546-62. doi: 10.3748/wjg.v25.i27.3546

28. Aoyama T, Kawabe T, Fujikawa H, Hayashi T, Yamada T, Tsuchida K, et al. Loss of Lean Body Mass as an Independent Risk Factor for Continuation of S-1 Adjuvant Chemotherapy for Gastric Cancer. Ann Surg Oncol (2015) 22 (8):2560-6. doi: 10.1245/s10434-015-4732-8

29. Lim HS, Lee B, Cho I, Cho GS. Nutritional and Clinical Factors Affecting Weight and Fat-Free Mass Loss After Gastrectomy in Patients With Gastric Cancer. Nutrients (2020) 12(7):1905. doi: 10.3390/nu12071905

30. Campbell PT, Jacobs ET, Ulrich CM, Figueiredo JC, Poynter JN, McLaughlin JR, et al. Case-Control Study of Overweight, Obesity, and Colorectal Cancer Risk, Overall and by Tumor Microsatellite Instability Status. J Natl Cancer Inst (2010) 102(6):391-400. doi: 10.1093/jnci/djq011

31. Ribic CM, Sargent DJ, Moore MJ, Thibodeau SN, French AJ, Goldberg RM, et al. Tumor Microsatellite-Instability Status as a Predictor of Benefit From Fluorouracil-Based Adjuvant Chemotherapy for Colon Cancer. N Engl J Med (2003) 349(3):247-57. doi: 10.1056/NEJMoa022289

32. Dong QT, Cai HY, Zhang Z, Zou HB, Dong WX, Wang WB, et al. Influence of Body Composition, Muscle Strength, and Physical Performance on the Postoperative Complications and Survival After Radical Gastrectomy for Gastric Cancer: A Comprehensive Analysis From a Large-Scale Prospective Study. Clin Nutr (2020) 40(5):3360-3369. doi: 10.1016/j.clnu.2020.11.007

33. Dijksterhuis WPM, Pruijt MJ, van der Woude SO, Klaassen R, Kurk SA, van Oijen MGH, et al. Association Between Body Composition, Survival, and Toxicity in Advanced Esophagogastric Cancer Patients Receiving Palliative Chemotherapy. J Cachexia Sarcopenia Muscle (2019) 10(1):199-206. doi: $10.1002 / \mathrm{jcsm} .12371$

34. Palmela C, Velho S, Agostinho L, Branco F, Santos M, Santos MP, et al. Body Composition as a Prognostic Factor of Neoadjuvant Chemotherapy Toxicity and Outcome in Patients With Locally Advanced Gastric Cancer. J Gastric Cancer (2017) 17(1):74-87. doi: 10.5230/jgc.2017.17.e8

35. Hacker UT, Hasenclever D, Linder N, Stocker G, Chung HC, Kang YK, et al. Prognostic Role of Body Composition Parameters in Gastric/ 
Gastroesophageal Junction Cancer Patients From the EXPAND Trial. J Cachexia Sarcopenia Muscle (2020) 11(1):135-44. doi: 10.1002/jcsm.12484

36. Black D, Mackay C, Ramsay G, Hamoodi Z, Nanthakumaran S, Park KGM, et al. Prognostic Value of Computed Tomography: Measured Parameters of Body Composition in Primary Operable Gastrointestinal Cancers. Ann Surg Oncol (2017) 24(8):2241-51. doi: 10.1245/s10434-017-5829-z

37. Doyle SL, Mongan AM, Donohoe CL, Pidgeon GP, Sherlock M, Reynolds JV, et al. Impact of Visceral Obesity and Metabolic Syndrome on the Postoperative Immune, Inflammatory, and Endocrine Response Following Surgery for Esophageal Adenocarcinoma. Dis Esophagus (2017) 30(6):1-11. doi: 10.1093/dote/dox008

38. Otani K, Kitayama J, Kaisaki S, Ishigami H, Hidemura A, Fujishiro M, et al. Early Gastric Cancer Shows Different Associations With Adipose Tissue Volume Depending on Histological Type. Gastric Cancer (2008) 11(2):8695. doi: 10.1007/s10120-008-0459-6

39. Ghorpade DS, Ozcan L, Zheng Z, Nicoloro SM, Shen Y, Chen E, et al. Hepatocyte-Secreted DPP4 in Obesity Promotes Adipose Inflammation and Insulin Resistance. Nature (2018) 555(7698):673-7. doi: 10.1038/nature26138

40. Vazzana N, Riondino S, Toto V, Guadagni F, Roselli M, Davi G, et al. ObesityDriven Inflammation and Colorectal Cancer. Curr Med Chem (2012) 19 (34):5837-53. doi: 10.2174/092986712804143349

41. Unamuno X, Gómez-Ambrosi J. Adipokine Dysregulation and Adipose Tissue Inflammation in Human Obesity. Eur J Clin Invest (2018) 48(9): e12997. doi: 10.1111/eci.12997

42. Kunisaki C, Makino H, Takagawa R, Sato K, Kawamata M, Kanazawa A, et al. Predictive Factors for Surgical Complications of Laparoscopy-Assisted Distal
Gastrectomy for Gastric Cancer. Surg Endosc (2009) 23(9):2085-93. doi: 10.1007/s00464-008-0247-8

43. Valencia S, Shindo K, Moriyama T, Ohuchida K, Tsurumaru D, Chua M, et al. Subcutaneous Fat Area as a Risk Factor for Extraction Site Incisional Hernia Following Gastrectomy for Gastric Cancer. Surg Today (2020) 50(11):141826. doi: 10.1007/s00595-020-02039-x

44. Takeuchi M, Ishii K, Seki H, Yasui N, Sakata M, Shimada A, et al. Excessive Visceral Fat Area as a Risk Factor for Early Postoperative Complications of Total Gastrectomy for Gastric Cancer: A Retrospective Cohort Study. BMC Surg (2016) 16(1):54. doi: 10.1186/s12893-016-0168-8

45. Ananth AA, Tai LH, Lansdell C, Alkayyal AA, Baxter KE, Angka L, et al. Surgical Stress Abrogates Pre-Existing Protective T Cell Mediated AntiTumor Immunity Leading to Postoperative Cancer Recurrence. PloS One (2016) 11(5):e0155947. doi: 10.1371/journal.pone.0155947

Conflict of Interest: The authors declare that the research was conducted in the absence of any commercial or financial relationships that could be construed as a potential conflict of interest.

Copyright (c) 2021 Gu, Zhang, Hong, Xu, Yang, Yan, Zhang, Chen, Zheng and Lin. This is an open-access article distributed under the terms of the Creative Commons Attribution License (CC BY). The use, distribution or reproduction in other forums is permitted, provided the original author(s) and the copyright owner(s) are credited and that the original publication in this journal is cited, in accordance with accepted academic practice. No use, distribution or reproduction is permitted which does not comply with these terms. 